\title{
Construindo Autonomia num Ambiente Cooperativo: Estações de Aprendizagem e a Coletividade dos Saberes
}

\author{
Lucinéia E. Happeck ${ }^{1,2}$, Crediné Silva de Menezes ${ }^{1}$ \\ ${ }^{1}$ Faculdade de Educação - Universidade Federal do Rio Grande do Sul (UFRGS) \\ Curso de Licenciatura em Pedagogia - Modalidade a Distância \\ Av. Paulo Gama, 110 - Farroupilha, Porto Alegre - RS, 90046-900 - RS - Brazil \\ ${ }^{2}$ Escola Municipal de Ensino Fundamental Professor Raimundo Fernandes de Oliveira, \\ Av. Rio Branco, 334 - Balneário Areias Brancas, Arroio do Sal - RS, 95585-000. \\ \{luhappeck, credine\}@gmail.com

\begin{abstract}
This paper seeks to prove the efficiency of creating collaborative environments as promoters of meaningful and autonomous learning. Through the observation and analysis of the qualitative results of the work with students of the fifth grade of a municipal public school, within a classroom space with applied constructivist-interactionist methodology, it was verified the development of autonomy in the students, making them more cooperative and concerned about the collective, as well as understanding the proper use of research work and the use of technologies as a learning tool.
\end{abstract}

Keywords: autonomy; cooperation; creativity; criticality.

Resumo. Este artigo busca comprovar a eficácia da criação de ambientes colaborativos como promotores de aprendizagens significativas e autônomas. Através da observação e análise dos resultados qualitativos do trabalho com alunos e alunas de quinto ano de uma escola pública municipal, dentro de um espaço de sala de aula com metodologia construtivista-interacionista aplicada verificou-se o desenvolvimento da autonomia nos estudantes, tornando-os mais cooperativos e preocupados com o coletivo, bem como compreendendo o uso adequado de trabalhos de pesquisa e uso das tecnologias como ferramenta de aprendizagem.

Palavras chave: autonomia; cooperação; criatividade; criticidade. 
VIII Congresso Brasileiro de Informática na Educação (CBIE 2019)

Anais dos Workshops do VIII Congresso Brasileiro de Informática na Educação (WCBIE 2019)

\section{Introdução}

Tentar fazer com que o espaço da sala de aula seja democrático, libertador, criativo e lúdico é, sobretudo demonstrar uma intencionalidade pedagógica de mudança e de busca pelo sentido da aprendizagem. Somente através da educação poderemos ter um futuro com mais cidadania e igualdade de direitos.

Este artigo apresenta uma prática docente em uma sala de aula do $5^{\circ}$. ano do ensino fundamental, em uma escola pública, tendo por objetivo produzir evidências que permitam argumentar em favor de que outro olhar sobre a prática e sobre as crianças pode promover autonomia, de forma colaborativa, tornando os saberes coletivos.

Assim, transformando o ambiente da sala de aula em um espaço de coletividade de saberes através estações de trabalho que possibilitam colaboração de todos e todas trazendo a autonomia em promoção através da cooperação.

A experiência e as experimentações realizadas na turma em estudo contribuíram para a transformação/construção de um sujeito educador também mais crítico e reflexivo no processo, por meio do reconhecimento do cotidiano escolar, bem como de cada sujeito aluno e aluna que compunha o grupo de estudo, considerando a sala de aula sob ponto de vista de um espaço de convívio social, de aprendizagens, descobertas e inovações que ocorrem simultaneamente, mas não da mesma forma e no mesmo tempo entre os envolvidos. Assim foi fundamental o respeito à individualidade dentro do tempo e espaço da sala de aula e todos estes aspectos foram abordados ao longo do trabalho.

O texto está organizado da seguinte forma: na seção 2 apresentamos o referencial teórico que o embasamento para a organização da experiência e para sua análise; na seção apresentamos a proposta de inovação pedagógica que desenvolvemos no semestre letivo considerado e, finalmente, na seção 4 apresentamos uma análise preliminar dos resultados obtidos.

\section{Referencial teórico}

A fundamentação teórica é a base de um estudo de caso e deve levar em consideração outras pesquisas e estudos realizados pautando as práticas desenvolvidas e com elas estabelecendo uma relação dialógica reflexiva. Quando se trata de uma questão de investigação envolvendo a educação, além dos teóricos que tratam do assunto, todo o aspecto legal da constituição da educação brasileira deve ser levado em consideração, respeitando os princípios norteadores estabelecidos legalmente. Autonomia, cooperação, tecnologias, planejamento, o reconhecimento da importância do brincar e do lúdico no processo educativo constituíram a base da fundamentação teórica apresentada ao longo deste trabalho.

\subsection{Autonomia na formação do sujeito}

Quando falamos de autonomia, entendemos esta como a busca por conhecimentos partindo da curiosidade do estudante. Paulo Freire argumenta que "O respeito à autonomia e à dignidade de cada um é um imperativo ético e não um favor que podemos ou não conceder uns aos outros" FREIRE (1996, p.24). Nesta frase o autor expõe o que é imprescindível no que se refere à constituição da autonomia dentro da sala de aula, a necessidade do respeito como princípio ético. Apresenta ainda a importância do 
reconhecimento do inacabamento pessoal do indivíduo educador, para que assim não cometa o erro de se perceber como detentor da razão, para que erroneamente não se coloque de forma autoritária minimizando o estudante e seus saberes, que somente reconheça seu inacabamento e assim a sua capacidade de também aprender, na troca e no diálogo com o estudante. Ainda no mesmo texto, o autor ainda coloca "a dialogicidade verdadeira, em que os sujeitos dialógicos aprendem e crescem na diferença, sobretudo, no respeito a ela, é a forma de estar sendo coerentemente exigida por seres que, inacabados, assumindo-se como tais, se tornam radicalmente éticos". $\mathrm{O}$ que leva a compreender que respeitando as diferenças e a autonomia conseguimos nos manter como sujeitos éticos em sala de aula.

Jean Piaget também nos fala da importância da autonomia e explica em (Piaget,1936) que o desenvolvimento da autonomia se dá em um processo que é mediado pelos adultos, crianças e adolescentes com os quais a criança convive e se relaciona. Os mecanismos de cooperação e reciprocidade são fundamentais a este processo de desenvolvimento.

A autonomia se manifesta quando a criança consegue explicar seu raciocínio para outra se fazendo compreender, quando numa relação dialógica consegue perceber também onde está errando e rever conceitos, assim a aprendizagem se concretiza. Ao conseguir tomar decisões por ela mesma, observando fatores que a levem ao melhor caminho, considerando então o seu ponto de vista e os pontos de vista das demais pessoas envolvidas no processo, dá-se a autonomia.

\subsection{Cooperação e o trabalho em equipe}

Segundo Piaget (1936), “A criança não é um ser passivo do qual se trate de rechear o cérebro, mas um ser ativo cuja tendência à pesquisa espontânea tem necessidade de alimentos". Dessa forma um destes "alimentos" é a troca, a relação com o outro, que instiga a curiosidade e faz com que o diálogo e a pesquisa sejam suportes de acesso a novos conhecimentos.

Para Piaget o indivíduo não se descobre a si próprio se não na medida em que aprende a conhecer os outros, o autor nos alerta também que a cooperação é essencial para conduzir à objetividade, uma vez que os indivíduos que cooperam entre si afastamse da sua perspectiva particular, renunciando aos seus próprios interesses para pensar em função da realidade em comum.

\subsection{Tecnologia na educação: aproximando e possibilitando novos saberes}

As tecnologias, notadamente a internet, não promovem distanciamentos, ao contrário, proporcionam aproximações entre as pessoas fazendo com que elas possam desenvolver suas diversas habilidades a partir de diálogos, em novos tempos e espaços. Neste novo cenário, o papel do professor passa a ter também o caráter investigativo, uma vez que este também parte para a pesquisa e assim consolida sua importância como mediador de conhecimentos, busca para ensinar, aprende para trocar. Para compreender e aceitar este novo papel que se desenha para a figura do professor em um espaço colaborativo é preciso que se tenha constituída a ideia de professorpesquisador-reflexivo, sujeito de sua ação e consciente de sua responsabilidade como articulador dos processos que ocorrem de forma simultânea em sala de aula. A sua presença ainda é necessária, embora não mais como foco direto dos estudantes, como 
VIII Congresso Brasileiro de Informática na Educação (CBIE 2019)

Anais dos Workshops do VIII Congresso Brasileiro de Informática na Educação (WCBIE 2019)

única fonte de conhecimentos, mas como sujeito mediador, como questionador e promotor de novas dúvidas para o estudante que busca o conhecimento.

\begin{abstract}
"O educador continua sendo importante, não como informador nem como papagaio repetidor de informações prontas, mas como mediador e organizador de processos. O professor é um pesquisador - junto com os alunos - e articulador de aprendizagens ativas, um conselheiro de pessoas diferentes, um avaliador dos resultados. O papel dele é mais nobre, menos repetitivo e mais criativo do que na escola convencional." MORAN (2010, p.3).
\end{abstract}

Assim Moran (2010) também nos leva a repensar a escola, não mais como convencional, mas como mutante e extremamente importante ao processo de inserção social ao qual devemos levar nossos educandos. É necessário também buscar conhecimento acerca da cultura atual, sem nos atrelar ao que parece ser estanque enquanto cultura de uma sociedade, isso implica em demonstrar a compreensão da cibercultura, que representa a cultura contemporânea, fortemente marcada pelas tecnologias digitais, são as trocas entre a sociedade, a cultura as novas tecnologias. Para discutirmos sobre este assunto precisamos compreender o quanto a comunicação evoluiu ao longo dos anos para que chegássemos à era digital.

Sampaio (2001 p. 2) expressa que a comunicação: “...é concebida como um processo dialógico através do qual sujeitos capazes de linguagem e ação interagem com fins de obter um entendimento". De acordo com Duvoisin at all (2016) o simples responder a uma questão não caracteriza o conversar: o conversar na escrita ocorre quando a interação se torna recursiva, quando se pode perceber, no entrelaçar das ferramentas digitais e das atividades, as coordenações processuais da aprendizagem.

Quando os autores trazem que o conversar na escrita se dá no momento da interação recursiva significa fazer com o que estudante reveja sua escrita e encontre novos questionamentos naquilo que ele próprio produziu, que perceba, por exemplo, ao criar um ambiente virtual de construção de suas aprendizagens que pode e deve retomar constantemente aquilo que ele mesmo escreveu, a fim de ressignificar conceitos, de ampliar suas aprendizagens, coordenando com auxílio do professor o seu próprio processo de aprendizagem.

Atualmente é imprescindível ao educador apropriar-se do uso das tecnologias como ferramenta de ensino-aprendizagem, ação-reflexão, reconhecer a cibercultura como possibilidade de relações sociais, desta forma é preciso que o uso das tecnologias não se dê apenas em meros exercícios de escrita, que poderiam ser facilmente feitos em cadernos ou computadores, sem alterar a intencionalidade pedagógica do mesmo, é necessário que se utilize a apropriação da cibercultura como elemento constitutivo da sociedade e que dela utilizemos para possibilitar a todos e todas estudantes do contexto em que estamos inseridos a inclusão digital.

\title{
2.7 As estações de aprendizagem/saberes e a contribuição na promoção da autonomia e colaboração
}

As estações de aprendizagem fazem parte do ensino híbrido que é, segundo Sassaki (2016) "abordagem que combina espaços, ferramentas e estilos de aprendizagem para 
VIII Congresso Brasileiro de Informática na Educação (CBIE 2019)

Anais dos Workshops do VIII Congresso Brasileiro de Informática na Educação (WCBIE 2019)

potencializar o desenvolvimento de cada aluno". A aplicação desta abordagem pode se dar de diversas formas e uma delas é através das estações de aprendizagem.

Ainda segundo o autor

A Rotação por Estações de Aprendizagem consiste em criar uma espécie de circuito dentro da sala de aula. Cada uma das estações deve propor uma atividade diferente sobre o mesmo tema central - ao menos uma das paradas deve incluir tecnologia digital. A ideia é que os estudantes, divididos em pequenos grupos de 4 ou 5 pessoas, façam um rodízio pelos diversos pontos. (SASSAKI, 2016, p. 1)

A ideia das estações de aprendizagem não precisa necessariamente ser seguida à risca e em alguns momentos adaptações são necessárias. É importante que cada estação seja independente e que nela ocorra uma atividade com início, meio e fim, que não dependa da participação em outra estação ou de algum conhecimento prévio. Os desafios de cada grupo devem ser resolvidos por eles, na estação em que estiverem atuando.

A reorganização e a inovação são características desta abordagem e permitem ao educador que monte a arquitetura pedagógica de suas estações de acordo com sua realidade e seus objetivos.

\begin{abstract}
Essa metodologia conta com três momentos essenciais: de interação entre alunos e professor (em que ele pode sanar dúvidas, orientar projetos, explicar conteúdos, fazer perguntas e provocar reflexões), de trabalho colaborativo (em que os estudantes trabalham em um projeto comum, propõem questões uns para os outros, organizam debates ou desenvolvem um produto que demonstre seu aprendizado) e de tecnologia (que pode incluir estudos individuais, exercícios online, pesquisas, games, entre outros). SASSAKI (2016, p.1)
\end{abstract}

O que numa outra leitura permite ao educador manter os três momentos, mas reorganizar a distribuição dos mesmos, criando uma estação para a discussão dos projetos, debates e ideias, outra para o trabalho cooperativo e lúdico e outra para o momento de contato e pesquisa com apoio tecnológico. A intencionalidade do trabalho permanece a mesma, envolver e aumentar o protagonismo dos estudantes, promovendo autonomia e cooperação.

O papel do professor no contato com cada estação deve ser o mesmo de mediar as aprendizagens, intervindo quando necessário, por solicitação de algum estudante ou por observação de necessidade.

Outra vantagem que esta forma de organização da sala de aula e do trabalho metodológico traz é a de garantir estímulos diversos aos estudantes, uma vez que outras visões de uma mesma situação problema trazem a construção do saber com mais autonomia.

\title{
3. Uma Experiência/Experimentação para a Vida
}

Toda a ação educativa que segue uma linha dialógica-reflexiva traz de alguma forma transformação para quem dela participa e ao realizar uma experiência que possibilitasse a criação de espaços cooperativos que visassem a construção da autonomia dos educandos a prática do educador também é revisitada, acrescida de mudanças que 
VIII Congresso Brasileiro de Informática na Educação (CBIE 2019)

Anais dos Workshops do VIII Congresso Brasileiro de Informática na Educação (WCBIE 2019)

refletem em uma educação para todos e todas, sobretudo no que se refere ao olhar dirigido a cada aluno e aluna e isso foi sentido e internalizado ao longo do processo que será descrito.

\subsection{A sala de aula sob o ponto de vista de um espaço de convívio}

Considerando a diversidade já descrita e enfatizando que a sala de aula deve ser um espaço de convívio social, de troca, de diálogo, de brincar e aprender coletivamente, o espaço físico da sala precisa de um novo olhar e assim, a redistribuição de mesas e cadeiras, saindo do tradicional "um atrás do outro" e/ou duplas, faz-se necessário. Muitas vezes o círculo é importante, pois permite o olhar a todos e todas de forma igualitária, porém, para que a aprendizagem seja construída, para que as bases norteadoras do planejamento sejam desenvolvidas deve-se utilizar distribuição das mesas e cadeiras em grupos, o que permite as estações de aprendizagem rotativas. Assim cada grupo pode interagir em estações diferenciadas, conforme o interesse e trabalho que estiver sendo realizado. As mesas devem ser realocadas em grupos, seguindo a arquitetura pedagógica da colaboração em grupos de trabalho e com esta organização o conhecimento do outro é facilitado.

As estações de trabalho são uma boa alternativa pois oferecem atividades diferenciadas e independentes umas das outras, de forma rotativa e que possibilitam a cada estudante desenvolver o que puder, dentro de seu tempo e no espaço coletivo. Transformar o ambiente em um lugar lúdico, criativo, que propicie e instigue a curiosidade faz com que a aprendizagem seja significativa e as trocas ricas.

Cada estação recebeu um nome, "espaço das ideias", "espaço lúdico", "espaço tecnológico" e dentro do planejamento estrategicamente construído, cada espaço traria à luz o desenvolvimento de habilidades e competências específicas.

A Estação tecnológica é a que tem os computadores, como acesso à internet, como ferramenta de trabalho e trocas. Assim, no espaço tecnológico os estudantes fazem suas pesquisas, digitam seus textos e constroem seus sites, trocando e auxiliando uns aos outros, mas dentro do seu próprio centro de interesse. O trabalho nessa estação se desenvolveu apoiado pela arquitetura pedagógica "Projetos de Aprendizagem", que será apresentado na seção 3.2. Como resultante do trabalho, cada aluno produziu um site para apresentar e compartilhar o desenvolvimento de sua investigação.

No espaço lúdico, enquanto participam de jogos de matemática, ciências, português, conhecimentos gerais realizam trocas e aprendizagens coletivas, sem a obrigatoriedade do aprender para mostrar. A avaliação através da observação é muito importante para que se perceba a evolução de cada estudante.

Blocos e lápis são o material de trabalho no "espaço das ideias" qualquer ideia, qualquer contribuição dos colegas deveria ser anotada, para organizar as pesquisas e as próximas atividades.

No espaço das ideias dialogar, escrever rascunhos, organizar ideias e pensamentos, de forma livre e mediada, dentro do interesse e curiosidade dos estudantes. Todo o trabalho nas estações deve ser mediado pelo professor.

Segundo Piaget (1936, p.4), o pensamento racional não é inato. 
VIII Congresso Brasileiro de Informática na Educação (CBIE 2019)

Anais dos Workshops do VIII Congresso Brasileiro de Informática na Educação (WCBIE 2019)

"A lógica constitui uma moral para o pensamento, quer dizer, ela não consiste em mecanismos inatos que se imponham segundo um determinismo inelutável, mas apenas em regras que se propõem à consciência intelectual e às quais esta pode submeter-se ou opor-se."

Assim, ainda segundo o autor, a verdade, como bem moral só se conquista pelo esforço livre, que nas crianças tem por condição natural a colaboração e o auxílio mútuo. Então, o espaço das ideias seria um local apropriado para esta troca que trouxesse através de pesquisas, discussões e diálogo a verdade sobre as curiosidades dos estudantes.

No espaço tecnológico, as ideias saem dos bloquinhos e vão para o computador, para a pesquisa e retornam ao bloquinho como novas sugestões e ressignificações. Cada estudante busca assuntos do seu interesse e isso torna a aula prazerosa.

O trabalho nas estações ocorre simultaneamente e os educadores em aula fazem a mediação, intercalando a visita aos grupos e intervindo quando necessário, diante de alguma observação ou respondendo às dúvidas dos estudantes.

\subsection{Uma experiência com a Arquitetura Pedagógica Projetos de Aprendizagem}

O uso tecnologias na sala de aula pode ser realizado por intermédio do conceito de Arquiteturas Pedagógicas (AP), uma abordagem didática concebida no contexto das pedagogias ativas tendo como suporte teórico as ideias construtivista de Jean Piaget e a Pedagogia da Pergunta de Paulo Freire(Carvalho, Nevado e Menezes, 2005). A proposição de uma AP considera desde a sua concepção o aporte das tecnologias digitais, notadamente a internet, que viabiliza as interações entre os estudantes e a mediação dos professores. A natureza ubíqua da internet viabiliza a redefinição do conceito de tempos e espaços, favorece o prosseguimento dos estudos extra-classe, potencializando a aprendizagem cooperativa, a socialização de produções, ampliando as trocas de ponto de vista e, constituindo-se como um ambiente digital propício às aprendizagem situadas.

Segundo (Carvalho, Nevado e Menezes, 2005):

"Arquiteturas Pedagógicas são definidas como "suportes estruturantes"
para a aprendizagem, entendidas como uma construção a partir da vivência
de experiências, de reflexões e metareflexões do sujeito, em interação com o
seu meio ambiente sócioecológico. Elas são configuradas pela confluência
de diferentes componentes, enfatizando-se: a abordagem pedagógica, o
software de apoio, a internet, a EAD e a concepção de tempo e espaço."

Uma dessas APs que tem sido bastante considerada no trabalho com alunos dos anos iniciais são os denominados Projetos de Aprendizagem (Fagundes, Sato e Maçada, 1999). Em um projeto de aprendizagem os estudantes buscam encontrar respostas para uma questão que lhes interessa, usando diferentes fontes de informação, onde coletam dados que são analisados e articulados para produzir um texto onde são apresentadas as conclusões da pesquisa (Magdalena e Costa, 2008). O trabalho de pesquisa segue uma abordagem cooperativa e os resultados são tornados públicos para promover a socialização e o debate entre estudantes. Em geral a socialização se materializa em um site na internet. 
VIII Congresso Brasileiro de Informática na Educação (CBIE 2019)

Anais dos Workshops do VIII Congresso Brasileiro de Informática na Educação (WCBIE 2019)

Nesta experiência a produção e a socialização foi realizada em sites construídos na plataforma pbworks (Wikipedia-pbwoks, 2019), que oferece um ambiente na internet, do tipo wiki (Wikipedia-wiki, 2019) para apoiar a construção cooperativa de hipertextos. Na primeira aula, todos os alunos normalmente querem sentar-se neste grupo, atraídos pelos computadores, já que nem mesmo imaginam o que vai acontecer. Depois de explicada a metodologia, diariamente deviam se organizar e saber em qual grupo sentar-se, em qual estação e isso é já uma característica da autonomia dos estudantes, pois ao naturalmente buscarem seus grupos acabam iniciando as atividades sem esperar esta ou aquela ordem da professora, simplesmente começando sua atividade naquela estação. Muitos estudantes podem demonstrar desconhecimento sobre como usar um computador e após uma explicação inicial da professora começam a tentar sozinhos e quando não conseguem, outros colegas do mesmo grupo e com mais experiência ou destreza naquela habilidade podem auxiliar, cooperando e mostrando a todos naquele momento como poderiam fazer.

A figura 1 apresenta um exemplo de páginas do site construído para responder à questão "Do que é feito uma lágrima?"
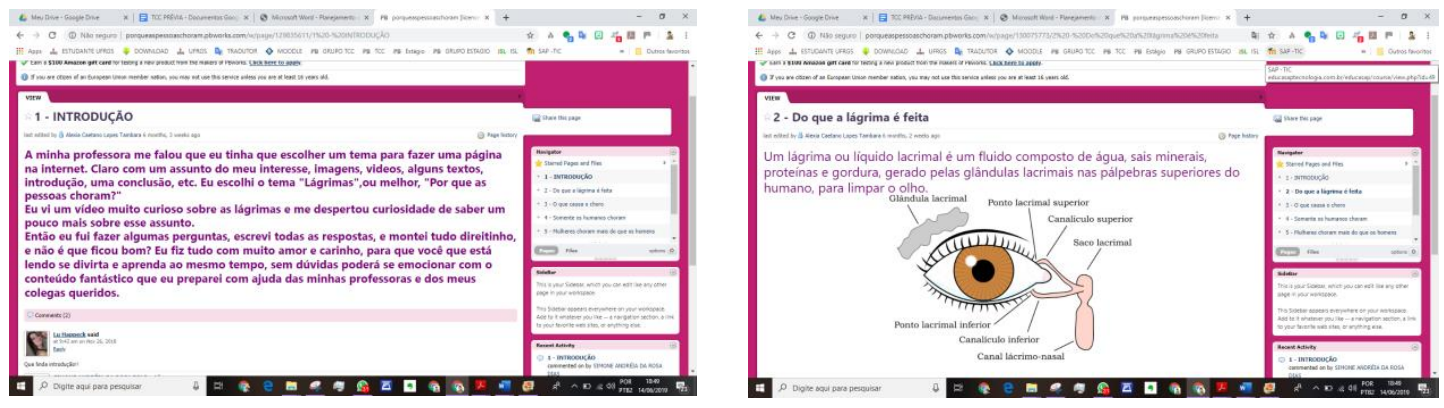

Figura 1: Páginas do Projeto "De que é feito uma lágrima" Fonte: (Happeck, 2019)

A produção das pesquisas sobre assuntos de interesse dos alunos acontece de forma espontânea, com momentos para organização das mesmas, mas respeitando o tempo de cada participante.

Piaget já colocava a importância do trabalho em equipe para auxiliar alunos com esta ou aquela dificuldade e que diante da oposição de ideias e formas de agir um poderia auxiliar o outro, como uma readaptação social. De acordo com Piaget (1936, p11):

\footnotetext{
"Existem, em toda classe, crianças preguiçosas ou simplesmente passivas, instáveis e agitadas, faladoras e retraídas, bem e mal dotadas. Qual é a influência do grupo sobre esses tipos opostos, comparada à do mestre?...Ora, - é necessário ceder à evidência - quando se analisa individualmente a maior parte desses casos de crianças mal adaptadas ao trabalho escolar, trata-se quase sempre de inadaptações sociais".
}

De modo geral desenvolvem uma pergunta de investigação e perguntas secundárias, pesquisam para tentar responder e o resultado pode ser registrado em um site, criado e construído de acordo com as preferências individuais. Nesta experiência definiu-se as seguintes seções obrigatórias para cada site: Introdução, Desenvolvimento, Imagens, Conclusão e Referências. 
VIII Congresso Brasileiro de Informática na Educação (CBIE 2019)

Anais dos Workshops do VIII Congresso Brasileiro de Informática na Educação (WCBIE 2019)

As intervenções são feitas em forma de comentários, em espaços específicos dos sites dos alunos o que favorece a geração de expectativas e interesse por parte dos estudantes.

\section{Considerações finais}

Finalizar o processo de análise de um trabalho tão intenso e rico não é tarefa fácil, portanto, a principal conclusão é justamente a condição de nosso inacabamento profissional e a certeza de que a formação continuada é tarefa constante do educador, a fim de acompanhar seus estudantes. O mérito a ser recebido será a possibilidade de aplicar inovações em sala de aula que repercutam positivamente na aprendizagem dos estudantes.

\subsection{Aprender com as limitações do todo}

Outra grande e valiosa lição diz respeito às limitações e compreensão de que embora nem todos cheguem ao final do processo da maneira esperada, todos chegarão com mudanças, com aprendizagens e em seu tempo e condições, crescendo.

Cada estudante, ao utilizar o construtor de sites (pbworks) como ferramenta de apresentação e de compilação dos resultados de sua pesquisa, mostra o quanto as tecnologias podem participar de um processo de colaboração, pois acabam por permitir a dialogicidade, a reflexão e as trocas, mesmo que à distância, possibilitando que os saberes ressignificados sejam revistos, reescritos, reordenados, de forma rápida e prática, ouvindo o outro e buscando constantemente o aperfeiçoamento.

\subsection{Analisando as aprendizagens sob o olhar reflexivo de pesquisador(a)}

O encantamento dos estudantes ao se apropriarem da tecnologia e usufruir dela para o registro de suas pesquisas, dando a cada página aspectos pessoais, depositando suas preferências, tornam o trabalho prazeroso e inesquecível.

Após a pesquisa construída, em suas escritas e percepções iniciais os estudantes começam a construção de seus sites, aprendendo a usar a ferramenta e criando ao todo seis páginas, com a exigência de introdução e conclusão, trabalhando assim a escrita, a pesquisa com seus elementos principais, depois de compreender a importância de cada um dos itens no processo. A ênfase deve ser dada à autoria e às referências quando necessárias, trabalhando desde cedo aspectos fundamentais na elaboração de trabalhos de pesquisa com legitimidade. O corpo do site de cada estudante deve ser moldado conforme o avanço das pesquisas, permitindo que cada estudante possa revisitar e reorganizar suas aprendizagens, conforme outras vão se consolidando.

A possibilidade de reescrever, reorganizar, sem o tradicional "apagar e escrever de novo" do caderno, dá um novo significado aos estudantes sobre o que é errar, permitindo que percebam os erros como alternativas de acerto futuro, através da reconstrução e reorganização do pensamento. Após a finalização dos sites um workshop de aprendizagens deve ser realizado, onde cada estudante expõe aos colegas suas aprendizagens, falam sobre suas descobertas e os saberes então se tornam coletivos.

$\mathrm{O}$ que se conclui é que o uso das estações de aprendizagem, associadas às tecnologias permite a ressignificação do espaço da sala, transforma a arquitetura pedagógica das aulas, possibilitando autonomia e aprendizagens significativas. 


\section{Referências Bibliográficas}

CARVALHO, R.A, NEVADO. R.A., MENEZES, C.S. Arquiteturas Pedagógicas para Educação a Distância: Concepções e Suporte Telemático. Anais do XVI Simpósio Brasileiro de Informática na Educação. Juiz de Fora - MG, 2005.

FAGUNDES, L.C., SATO, L.S., MAÇADA, D. L. Aprendizes do Futuro - as inovações já começaram. Brasília, MEC, 1999.

FREIRE, Paulo. Pedagogia da autonomia: saberes necessários à prática educativa / Paulo Freire. - São Paulo: Paz e Terra, 1996. - (Coleção Leitura)

. Pedagogia da Esperança: Um reencontro com a Pedagogia do Oprimido.

Rio de Janeiro, Paz e Terra, 1992.

HAPPECK. L.H. Construindo Autonomia num Ambiente Cooperativo: Estações de Aprendizagem e a Coletividade dos Saberes, Trabalho de Conclusão de Curso, PEAD/UFRGS, 2019.

MAGDALENA, B.C., COSTA, I. E. T. Revisitando os Projetos de Aprendizagem, em tempos de web 2.0. Simpósio Brasileiro de Informática na Educação, Fortaleza-CE, 2008.

MOURA, A. C. O. S. ; VANIEL, Berenice Vahl ; LAURINO, Débora Pereira . Conversar pela Escrita: Possibilidades de Aprendizagens na Educação a Distância. In: Moura, Ana Carolina de Oliveira Salgueiro de; Vaniel, Berenice Vahl; Laurino, Débora Pereira. (Org.). EDUCAR EM INTERAÇÕES DIGITAIS: Pesquisa, Tecnologias e Formação de Professores. 1ed.Rio Grande: Ed. da FURG, 2016, v. 1, p. 277-301.

MORAN, José Manuel. A integração das tecnologias na educação. Disponível em: $<$ http:// http://www.uab.furg.br/prof/moran/integracao.htm>. Acesso em: 11 fev. 2010.

PIAGET.Jean. (1936) O trabalho por equipes na escola. Revista de Educação - Diretoria do Ensino do Estado de São Paulo set/dez 1936. Tradução Luiz G. Fieury. Adaptação para o português moderno: Andrea A. Botelho - Laboratório de Psicopedagogia do Instituto de Psicologia da USP, 1993.

(1977). O julgamento moral da criança. Rio de Janeiro: Mestre Jou (Trabalho original publicado em 1932).

SAMPAIO, I. S. V. Conceitos e modelos da comunicação. Ciberlegenda, ${ }^{\circ}$ 5, 2001. Disponível em http://www.uff.br/mestcii/ines1.htm. Acesso em 27/02/2009

SASSAKI, Cláudio. Para uma aula diferente, aposte na Rotação por Estações de Aprendizagem. Revista Nova Escola. Outubro de 2016. Disponível em https://novaescola.org.br/conteudo/3352/blog-aula-diferente-rotacaoestacoes-deaprendizagem. Acesso em 27 de abril de 2018.

Wikipedia-pbworks (2019) https://pt.wikipedia.org/wiki/PBworks (acessado em $06 / 10 / 2019)$

Wikipedia-wiki (2019) https://pt.wikipedia.org/wiki/Wiki (acessado em 06/10/2019) 